\title{
The association of high-sensitivity c-reactive protein and other biomarkers with cardiovascular disease in patients treated for HIV: a nested case-control study
}

\author{
Andrea De Luca ${ }^{1,10^{*}}$, Katleen de Gaetano Donati ${ }^{2}$, Manuela Colafigli ${ }^{2}$, Alessandro Cozzi-Lepri ${ }^{3}$, Amalia De Curtis ${ }^{4}$, \\ Andrea Gori ${ }^{5}$, Laura Sighinolfi ${ }^{6}$, Andrea Giacometti ${ }^{7}$, Maria Rosaria Capobianchi ${ }^{8}$, Alessandro D'Avino ${ }^{2}$, \\ Licia lacoviello ${ }^{4}$, Roberto Cauda ${ }^{2}$ and Antonella D'Arminio Monforte ${ }^{9}$
}

\begin{abstract}
Background: Elevated high-sensitivity C-reactive protein (hsCRP) increases the risk of cardiovascular disease (CVD) in the general population, but its role as a predictive marker in HIV-positive patients remains unclear. Aim of the study was to evaluate whether hsCRP or other biomarkers are independent predictors of CVD risk in HIV-infected patients.

Methods: Retrospective, nested case-control study. HIV-positive men and women (35-69 years of age) receiving combination antiretroviral therapy (CART) were included. Cases $(n=35)$ had a major CVD event. Controls $(n=74)$ free from CVD events for at least 5 years from starting ART were matched on diabetes and smoking. HsCRP, D-dimer, P-selectin, interleukin-6 (IL-6), tissue plasminogen activator, plasminogen activator inhibitor-1 levels were measured.

Results: High hsCRP was associated with CVD risk, independently of traditional cardiovascular risk factors, HIV replication and the type of ART received at the time of sampling (adjusted odds ratio 8.00 [1.23-51.94] comparing $>3.3 \mathrm{mg} / \mathrm{L}$ with $<0.9 \mathrm{mg} / \mathrm{L} ; P=0.03$ ). Higher IL-6 and P-selectin levels were also independently associated with increased CVD risk, although the association was weaker than for hsCRP. Higher total cholesterol and lower HDL cholesterol increased CVD risk, independent of hsCRP.
\end{abstract}

Conclusion: hsCRP may be a useful additional biomarker to predict CVD risk in HIV-infected patients receiving CART.

Keywords: Biomarkers, Cardiovascular disease, HIV, hsCRP

\section{Background}

Combination antiretroviral therapy (cART) has substantially reduced HIV-related morbidity and mortality [1]. As a result, HIV-infected people have longer life-expectancy and the focus of therapy has shifted to long-term management of the infection, particularly treatment-related side-effects and comorbidities. Cardiovascular disease (CVD) has received particular attention, as it is associated with considerable morbidity and mortality [2], and there is

\footnotetext{
* Correspondence: deluca.andrea@fastwebnet.it

${ }^{1}$ University Division of Infectious Diseases, University Hospital of Siena, Siena, Italy

${ }^{10}$ Istituto di Clinica delle Malattie Infettive, Università Cattolica del Sacro Cuore, Largo F Vito 1, 00168, Roma, Italy

Full list of author information is available at the end of the article
}

cumulating data showing that HIV-infected patients are at higher risk of CVD than uninfected controls [3,4]. However, controversy exists over the relative contribution of host factors (e.g. smoking, hypertension, diabetes, male sex and older age), rather than the virus itself or use of cART to this increased risk. For HIV infection and cART, this effect may occur via their modification of traditional risk factors [5], as well as pathogenic pathways leading to atherosclerosis and CVD (e.g. inflammation and endothelial dysfunction) [3,6-10].

Although several studies have suggested a positive association between CART and CVD risk [3,11,12], there is also evidence that cART may improve endothelial function and protect against atherosclerosis $[13,14]$. Furthermore, differences exist in the relative risk of CVD between, and within,

\section{Biomed Central}


antiretroviral drug classes [15-21]. In particular, the Data Collection on Adverse Events of Anti-HIV Drugs (D:A:D) Study Group found an association between the use of specific protease inhibitors, of abacavir and of didanosine and an increased risk of myocardial infarction [22], but not all subsequent studies have confirmed this result [23].

Research into CVD risk factors in the general population has identified a number of predictive biomarkers, such as apolipoprotein B, total cholesterol, interleukin-6 (IL-6), serum amyloid A, D-dimer, tissue plasminogen activator (t-PA), plasminogen activator inhibitor-1 (PAI-1), P-selectin, intercellular adhesion molecule 1 (ICAM-1), vascular adhesion molecule 1 (VCAM-1) and, most importantly, C-reactive protein (CRP) as determined by high sensitivity techniques (hsCRP) [24-29]. HsCRP levels <1.0 mg/L, $1.0-3.0 \mathrm{mg} / \mathrm{L}$ and $>3.0 \mathrm{mg} / \mathrm{L}$ indicate low, average and high CVD risk, respectively [30].

Given the increased risk of CVD in HIV-infected patients, the predictive role of such biomarkers in this patient population is of interest. Several potential CVD markers have been investigated in HIV-positive patients, including lipoprotein particles, measurements of carotid artery intima-media thickness and of arterial stiffness, tumor necrosis factor- $\alpha$, IL-6, IL-10, myeloperoxidase, platelet (P)-selectin, leptin, D-dimer, adiponectin, soluble VCAM-1, ICAM-1 and ICAM-3, and hsCRP [31-33]. A recent analysis on the SMART study found an association between CRP, IL-6 and d-dimer and the risk of CVD events [34].

Our primary objective was to evaluate whether hsCRP predicts CVD risk in HIV-infected patients, independently of other established risk factors, using the data of persons enrolled in two Italian cohorts. Our secondary objective was to investigate the association between other biomarkers and CVD.

\section{Methods \\ Participants}

We studied patients enrolled in two cohort studies; the Icona Foundation Cohort and the Catholic University of the Sacred Heart (CUSH) clinical database, Rome. In CUSH, data have been collected as part of routine clinical care since 1997 (full details are reported elsewhere [35]). The Icona Foundation Study includes HIV-positive patients presenting at 67 infectious disease centers across Italy and represents the continuation of the Italian Cohort of Antiretroviral-Naïve Patients (I.Co.N.A) study, which has previously been described [36]. After enrolment, follow-up clinical visits occur approximately every 6 months in the Icona Foundation Study and every 3 months in CUSH.

All patients provided written consent to participate in Icona Foundation Study and in CUSH, following procedures in accordance with the ethical standards of the responsible committee on human experimentation and the Helsinki
Declaration. In both studies, patients informed consent includes a specification for use of samples for further research in HIV. No specific consent for inclusion in the current analysis was therefore needed. The studies and the corresponding informed consents were approved by the Ethics Committees of the various ICONA clinical sites (see Appendix) and that of the Catholic University for CUSH. Inclusion criteria for this analysis were age 35-69 years and no history of a major CVD event before starting cART and no evidence of any other inflammatory disorder over the 3 months prior to the date of the stored plasma sample. Exclusion criteria were current use of active hormonal-based therapy and of therapy with anti-inflammatory drugs or statins. A small proportion of patients had used these drugs prior to the date of the stored sanple.

\section{Analysis design}

We conducted a retrospective, matched case-control study nested within CUSH and the Icona Foundation Study involving HIV-infected patients with CVD (cases) or without CVD (controls). CVD cases were defined as HIV-infected patients who had a major cardiovascular event (acute myocardial infarction; stable or unstable angina or were undergoing myocardial revascularization procedures) while receiving cART (a regimen including at least 3 antiretrovirals), and for whom at least one plasma sample was stored before the CVD event. Within each cohort, HIV-infected controls (a minimum of two per each case) were defined as patients who were currently free of CVD events (i.e. had never developed CVD events), had at least 5 years of follow-up after cART initiation and had at least one plasma sample stored over the observation period.

Cases and controls were matched on previous history of diabetes and smoking status. The 'index time' for analysis was fixed at the date of the CVD event for cases and at last follow-up for controlsBecause date of sample for controls was on average much more recent than that of cases, calendar year and time between the date of sample and the index time were included as an additional adjusting factor in the multivariable analyses.

\section{Sample collection}

In CUSH, plasma samples are collected each time a viral load assay is performed (i.e. approximately every 3 months), and stored at $-80^{\circ} \mathrm{C}$. In the Icona Foundation Study, plasma samples are stored at the time of enrolment and at least once a year. In both cohorts, plasma samples are collected using Vacutainer ${ }^{\circledast}$ collection tubes (lavender top, containing ethylenediaminetetraacetic acid, Becton Dickinson, New Jersey, USA). In the case of ICONA foundation Study, samples are initially kept frozen at the various clinical sites at $-20^{\circ} \mathrm{C}$ or $-80^{\circ} \mathrm{C}$ and subsequently shipped using 
dry ice to a central repository in Rome, Italy, where they are kept at $-80^{\circ} \mathrm{C}$ until use for retrospective analysis. Dates of sampling were (ranges) 1999-2008 for cases and 2006-2008 for controls for CUSH, and 1998-2004 for cases and 2000-2004 for controls for the Icona Foundation Study. As a general rule, the most recent plasma sample stored before the analysis index time was analyzed in both cases and matching pair of controls (late samples). However, for some cases and controls, if more than one stored sample was available, biomarkers were measured using an additional earlier sample (early samples). To avoid bias, laboratory personnel was blind to whether the sample was coming from a case or a control. Samples, which were labelled with a unique identifier so that they could be linked with patients ID and their clinical data for statistical analysis, were analyzed in random order.

\section{Biochemical analyses}

Total cholesterol and HDL were measured using standard techniques by local laboratories, while biomarkers were analyzed by the Laboratory of Genetic and Environmental Epidemiology, Catholic University of Campobasso, Italy. hsCRP was measured by nephelometry using an automatic analyzer (ILab 350, Instrumentation Laboratory, Milan, Italy). Quality control was performed using an internal laboratory standard; the inter-day coefficient of variation $(\mathrm{CV})$ was $2 \%$. D-Dimer was evaluated utilizing a latex particle-enhanced immunoturbidimetric assay (IL ACL9000, Instrumentation Laboratory, Milan, Italy). Quality control was performed using an in-house citrate plasma pool; inter-and intra-day CV was $7.6 \%$ and $5.4 \%$, respectively. P-selectin (Bender MedSystems Europe, Vienna, Austria), IL-6 (R\&D System Europe, Abingdon, UK), t-PA and PAI-1 (American Diagnostica Inc. GmbH, Pfungstadt, Germany) were measured utilizing commercially available enzyme-linked immunosorbent assay (ELISA) kits, as specified by the manufacturers. The intra-assay $\mathrm{CV}$, using in-house citrate plasma, were, according to the manufacturer, $4.3 \%, 10.5 \%, 4.8 \%$ and $9.8 \%$ respectively.

The detection limit of the different assays were $1.06 \mathrm{ng} / \mathrm{ml}$ for P-selectin, $1.0 \mathrm{ng} / \mathrm{ml}$ for t-PA, $1.0 \mathrm{ng} / \mathrm{ml}$ for PAI-1 and $0.70 \mathrm{pg} / \mathrm{ml}$ for IL-6.

\section{Sample size calculation and statistical analysis}

By setting the type I error $\alpha$ at $5 \%$, and assuming that $40 \%$ of patients had a hsCRP level above $3 \mathrm{mg} / \mathrm{L}$ [30] and two controls per case, we calculated that 35 cases and 70 controls were necessary to achieve $80 \%$ power to detect an OR for CVD risk of 3.3 for a hsCRP level above the pre-defined threshold (vs. below $1 \mathrm{mg} / \mathrm{L}$ ). Smaller effects were expected for the other biomarkers which the study was not powered on.
Summary statistics and illustrations appropriate for matched case-control studies were used to summarize key findings [37]. Conditional logistic regression analysis for matched case-control studies was performed to evaluate the association between the baseline characteristics of the patients as well as the levels of each biomarker with the risk of CVD events. Separate analyses were performed using the late samples as well as using all samples combinedby tertiles of each biomarker (for the early samples, sparse data led to numerical problems in the multivariable analysis, resulting in an unstable model); cut-offs for the tertiles were chosen using the distribution of the measures in the combined dataset. For hsCRP, sensitivity analyses were also performed using the categories of $<1,1-3$ and $>3 \mathrm{mg} / \mathrm{L}$ as these had been clinically validated in the general population.

Models with $\log _{2}$ transformed biomarker levels were also used, estimating the increased risk of CVD associated with a one $\log _{2}$ difference in biomarker levels. Separate models were fit for each biomarker and, because of the large number of parameters involved, we decided a priori not to fit the model mutually controlling for all biomarkers. The following covariates assessed at the date of stored samples were considered for the adjusted analyses: calendar year, duration of time between the date of sample and the analysis time, age, total cholesterol, $\mathrm{HDL}, \mathrm{CD} 4^{+}$cell count and viral load, cumulative exposure to nonnucleoside reverse transcriptase inhibitors (NNRTIs), nucleoside reverse transcriptase inhibitor (NRTIs) and protease inhibitor (PIs) prior to sample, and co-infection with hepatitis B or C. [38]. Sensitivity analyses, were performed on the combined samples set additionally controlling for one of these factors at the time: body mass index (BMI), estimated glomerular filtration rate (eGFR, by the MDRD formula) and prior use of statins. In the analysis using the combined data set, standard errors were adjusted for non-independence between biomarkers coming from the same individual using the cluster option for clogit in STATA [39]. All statistical analyses were performed using SAS version 9.1, Cary, North Carolina, United States and STATA software (StataCorp. 2008. Stata Statistical Software: Version 10.1, College Station, Texas, USA). All tests were two-sided and assumed a level of significance of 0.05 .

\section{Results}

\section{Baseline characteristics}

We studied 109 patients (35 cases, 74 controls) of whom 17 cases, 40 controls were from CUSH and 18 cases, 34 controls from the Icona Foundation Study. The distribution of the matching variables in cases and controls was: smokers/ diabetics $(3 ; 4)$, non-smokers/diabetics $(4 ; 8)$, smokers/nondiabetics (22;50), non-smokers/non-diabetics (6;12). Characteristics of cases and controls at the time of the late samples are summarized in Table 1. Compared with 
Table 1 Main characteristics of cases and matched controls at time of late sample

\begin{tabular}{|c|c|c|c|}
\hline \multirow[t]{2}{*}{ Characteristic } & \multirow{2}{*}{$\begin{array}{c}\text { Cases } \\
(n=33)^{*}\end{array}$} & \multirow{2}{*}{$\begin{array}{l}\text { Controls } \\
(n=71)^{*}\end{array}$} & \multirow[t]{2}{*}{ p-value $\neq$} \\
\hline & & & \\
\hline \multicolumn{4}{|l|}{ Age, years } \\
\hline median (IQR) & $47(42,53)$ & $45(39,49)$ & 0.139 \\
\hline \multicolumn{4}{|l|}{ Gender, n(\%) } \\
\hline Female & $1(3 \%)$ & $8(11 \%)$ & 0.205 \\
\hline \multicolumn{4}{|l|}{ Mode of HIV trasmission, n (\%) } \\
\hline IDU & $13(39 \%)$ & $21(30 \%)$ & \\
\hline Homosexual contacts & $7(21 \%)$ & $18(25 \%)$ & 0.365 \\
\hline Heterosexual contacts & $12(36 \%)$ & $24(34 \%)$ & 0.657 \\
\hline Other/Unknown & $1(3 \%)$ & $8(11 \%)$ & 0.143 \\
\hline \multicolumn{4}{|l|}{ Co-infection with HBV or HCV, n (\%) } \\
\hline Yes & $16(48 \%)$ & $26(37 \%)$ & 0.224 \\
\hline \multicolumn{4}{|l|}{ CD4 count, cells $/ \mathrm{mm}^{3}$} \\
\hline Median (IQR) & $550(451,730)$ & $525(370,768)$ & 0.805 \\
\hline \multicolumn{4}{|l|}{ HIV RNA, $\log _{10}$ copies $/ \mathrm{mL}$} \\
\hline Median (IQR) & $2.1(1.7,4.0)$ & $1.7(1.7,2.7)$ & 0.164 \\
\hline Median total cholesterol (IQR) & & & 0.006 \\
\hline $\mathrm{nmol} / \mathrm{L}$ & $5.4(4.6,6.3)$ & $4.9(4.0,5.6)$ & \\
\hline $\mathrm{mg} / \mathrm{dL}$ & $209.0(180.0,247.0)$ & $192.0(155.0,217.0)$ & \\
\hline Median HDL-cholesterol (IQR) & & & 0.130 \\
\hline $\mathrm{nmol} / \mathrm{L}$ & $2.1(1.8,2.3)$ & $2.3(1.9,2.6)$ & \\
\hline $\mathrm{mg} / \mathrm{dL}$ & $40.0(35.0,45.0)$ & $44.0(37.0,51.0)$ & \\
\hline CART-treated before late sample, $n(\%)$ & & & 0.115 \\
\hline Yes & $29(88 \%)$ & $54(76 \%)$ & \\
\hline AIDS diagnosis, n (\%) & & & 0.586 \\
\hline Yes & $6(18 \%)$ & $16(23 \%)$ & \\
\hline Cumulative exposure to NRTI, months & & & 0.003 \\
\hline Median (IQR) & $51(27,102)$ & $121(40,145)$ & \\
\hline Cumulative exposure to NNRTI, months & & & 0.021 \\
\hline Median (IQR) & $3(0,27)$ & $30(0,77)$ & \\
\hline Cumulative exposure to $\mathrm{Pl}$, months & & & 0.020 \\
\hline Median (IQR) & $26(8,38)$ & $52(11,89)$ & \\
\hline Calendar year of sample & & & $<.001$ \\
\hline Median (IQR) & $2003(2001,2006)$ & $2008(2003,2008)$ & \\
\hline Median duration between late sample and analysis time, months & $3(2,12)$ & $8(7,28)$ & 0.051 \\
\hline Prior use of statins ${ }^{\circ}, \mathrm{n}(\%)$ & & & 0.263 \\
\hline Yes & $5(15 \%)$ & $4(6 \%)$ & \\
\hline Body Mass Index§, kg/m² & & & 0.366 \\
\hline Median (IQR) & $23.7(21.7,25.8)$ & $23.1(21.3,26.3)$ & \\
\hline eGFR^ (MDRD formula), $\mathrm{ml} / \mathrm{min} / 1.73 \mathrm{~m}^{2}$ & & & 0.637 \\
\hline Median (IQR) & $92(80,116)$ & $86(77,98)$ & \\
\hline
\end{tabular}

*2 cases and 4 controls had no late sample available.

\#from fitting a conditional logistic regression model (continuous variables in log scale).

${ }^{\circ} \mathrm{C}$ urrent use (i.e. use during the 3 months before sample) was an exclusion criterion.

$\S$ available in 21 cases and 58 controls.

$\wedge$ available in 24 cases and 56 controls. 
controls, cases had higher total cholesterol, a shorter cumulative exposure to ART, regardless of drug class and alate sample that was stored less recently, but closer to the analysis time (Table 1). The index pathology for the 35 cases was: acute myocardial infarction $(n=30)$, revascularization procedures $(n=1)$, stable or unstable angina $(\mathrm{n}=4)$.

\section{Biomarkers and risk of CVD}

The 35 cases contributed 68 samples ( 35 early and 33 late samples) while the 74 controls contributed 145 samples (74 early and 71 late samples) for biomarkers analysis. In the unadjusted analysis comparing median values of biomarkers between cases and controls, the only biomarker consistently showing a higher median value in cases compared with controls was hsCRP, both in the analysis using the early samples (2.99 [IQR 1.13-5.99] $\mathrm{mg} / \mathrm{L}$ in cases versus $1.62[0.44-3.50] \mathrm{mg} / \mathrm{L}$ in controls, $P=0.09$ ) and late samples (see Figure $1, P=0.002$ ). Higher median values were observed for t-PA in early samples (13.6 [11.1-17.0] $\mathrm{ng} / \mathrm{mL}$ in cases versus $8.9[6.3-13.2] \mathrm{ng} / \mathrm{mL}$ in controls, $\mathrm{p}<0.001$ ) and P-selectin in late samples (Figure 1) in cases as compared to controls.

For hsCRP, in early samples, $6 / 35$ (17\% of cases) had levels in the lowest tertile compared with $26 / 74$ (35\% of controls). In contrast, the corresponding percentages with levels of hsCRP falling in the highest tertile were $14 / 35(40 \%)$ and $26 / 74$ (26\%) for cases and controls, respectively. Similarly, for the late samples alone, 5/33 (15\%) of cases and 23/71 (32\%) of controls had hsCRP values in the lowest tertile vs. $14 / 33$ (42\%) and $14 / 71$ $(18 \%)$ in the highest tertile. For the combined data set, the corresponding values were $11 / 68(16 \%)$ for cases and
49/145 (34\%) for controls with hsCRP levels in the lowest tertile vs. $28 / 68(41 \%)$ and $33 / 145(23 \%)$ in the highest tertile.

Based on univariable and multivariable analyses, on late samples (Table 2) and the combined dataset (Table 3) a significantly increased risk of CVD events was observed for higher values of hsCRP, IL-6 and P-selectin, analyzed as categorical variables (Tables $2 \mathrm{a}$ and $2 \mathrm{a}$ ), although a consistent association using the different sets of data was observed only for hsCRP and, less so, for P-selectin. Multivariable estimates were adjusted for all factors shown in the footnote of Tables 2 and 3. Similar results were obtained by analyzing biomarkers as log-transformed continuous variables (Tables $2 \mathrm{~b}$ and $2 \mathrm{~b}$ ), with significant associations with hsCRP and P-selectin.

None of the other considered biomarkers showed an independent association with the risk of CVD. Covariate adjustment showed that the magnitude of the association was underestimated in the unadjusted analysis as adjusted OR were even higher, especially for hsCRP. Use of the combined data set provided more precise estimates, as a result of increased statistical power (Tables 3a and b).

Sensitivity analyses using the clinically validated hsCRP categories [30] showed similar results. In the late samples data set, adjusted ORs for CVD events were 6.45 (95\% CI, 0.64 to $64.42 ; P=0.112$ ) for values of $1-3 \mathrm{mg} / \mathrm{L}$ and 13.69 (95\% CI, 1.35 to $138.9 ; P=0.027$ ) for values $>3 \mathrm{mg} / \mathrm{L}$, as compared to values of $<1 \mathrm{mg} / \mathrm{L}$. The corresponding values for the combined data set were $6.5(95 \% \mathrm{CI}, 1.0$ to 41.7 ; $P=0.047$ ) and 11.4 (95\% CI, 1.8 to $72.3 ; P=0.010$ ).

We performed additional sensitivity analyses on the combined early and late samples dataset. In the

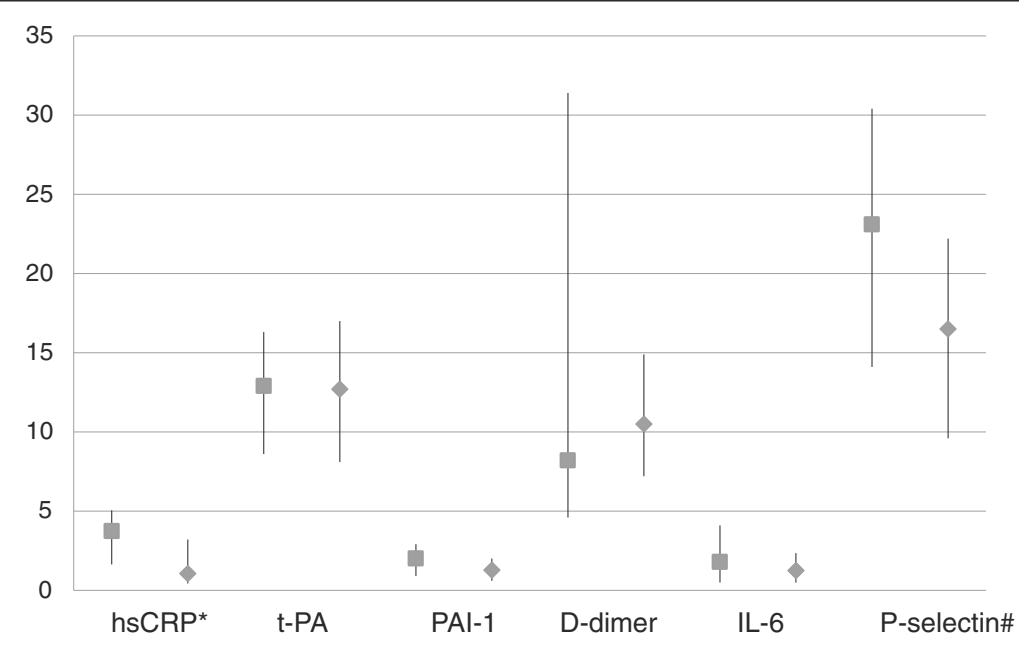

Figure 1 Plasma levels of biomarkers on late samples in cases and matched controls. Values indicate medians (full squares in cases and full diamonds in controls), bars indicate interquartile ranges. hsCRP = high-sensitivity C-reactive protein in $\mathrm{mg} / \mathrm{L} ; \mathrm{t}-\mathrm{PA}=$ tissue plasminogen activator in $\mathrm{ng} / \mathrm{mL}$; D-dimer in $\mu \mathrm{g} / 100 \mathrm{~mL}$; PAl-1 = plasminogen activator inhibitor-1 in $\mu \mathrm{g} / 10 \mathrm{~mL} ; \mathrm{LL}-6=$ interleukin-6 in pg/mL; P-selectin = platelet selectin in $\mu \mathrm{g} / 100 \mathrm{~mL}$. ${ }^{*} \mathrm{p}=0.002 ; \# \mathrm{p}=0.005$ from fitting a conditional logistic regression (biomarkers in log scale) comparing cases and controls. 
Table 2 Univariable and multivariable odds ratios for cardiovascular events according to biomarkers in late samples

t-PA, $\mathbf{n g} / \mathbf{m l}$
$<=8.7(n=27)$
$8.7-14.8(n=26)$
$>14.8(n=35)$
Not measured $(n=16)$

PAl-1, ng/ml

$$
\begin{aligned}
& <=112(n=36) \\
& 112-207(n=27) \\
& >207(n=29)
\end{aligned}
$$

Not measured $(n=12)$

\section{D-dimer, $\mathbf{n g} / \mathbf{m l}$}

$<=67(\mathrm{n}=18)$

67-125 $(n=27)$

$>125(n=28)$

Not measured $(n=31)$

\section{hsCRP, mg/L}

$<0.9(n=28)$

0.9-3.3 $(n=31)$

$>3.3(n=28)$

Not measured $(n=17)$

\section{IL-6, pg/ml}

$$
\begin{aligned}
& <0.3(n=20) \\
& 0.3-1.9(n=34) \\
& >1.9(n=37) \\
& \text { Not measured }(n=13)
\end{aligned}
$$

\section{P-selectin, $\mathrm{ng} / \mathrm{ml}$}

$<157(\mathrm{n}=38)$

157-236 $(n=28)$

$>236(n=25)$

Not measured $(n=13)$
1.00

$1.56(0.48,5.10)$

$0.99(0.31,3.14)$

$2.99(0.81,10.95)$

1.00

$1.15(0.33,3.96)$

$2.99(0.98,9.12)$

$3.62(0.91,14.49)$

1.00

$0.55(0.15,2.10)$

$0.72(0.20,2.61)$

$1.70(0.51,5.62)$

1.00

$1.59(0.46,5.55)$

$4.28(1.28,14.36)$

$2.54(0.64,10.11)$

1.00

$0.67(0.20,2.31)$

$1.39(0.43,4.46)$

$2.03(0.48,8.50)$

1.00

$1.23(0.36,4.19)$

$4.39(1.43,13.45)$

$3.41(0.88,13.20)$
0.459

0.989

0.099

0.828

0.054

0.069

0.384

0.617

0.387

0.467

0.019

0.187

0.529

0.580

0.334

0.744

0.010

0.075
1.00

$2.54(0.52,12.31)$

0.247

$0.35(0.05,2.31)$

0.278

$4.06(0.50,32.74)$

0.188

1.00

$0.55(0.11,2.74)$

0.468

$3.20(0.75,13.76)$

0.118

$3.02(0.23,39.02)$

0.397

1.00

$0.32(0.06,1.84)$

0.202

$0.63(0.12,3.28)$

0.585

$0.55(0.10,2.90)$

0.482

1.00

$5.25(0.56,49.67) \quad 0.148$

$10.71(1.03,111.0) \quad 0.047$

$3.88(0.23,66.29) \quad 0.349$

1.00

$0.13(0.02,0.86)$

0.034

$0.36(0.06,2.05)$

0.249

$0.64(0.04,9.07)$

0.738

1.00

$1.40(0.29,6.87)$

0.676

$3.94(0.82,18.88)$

0.086

0.407

(b)

Biomarkers as continuous variables (Log Scale)

t-PA, ng/ml

Per log2 higher

$0.97(0.55,1.74)$

0.926

$0.78(0.35,1.76)$

0.554

PAl-1, ng/ml

Per log2 higher

$1.47(0.96,2.24)$

0.073

$1.40(0.81,2.42)$

0.233

D-dimer, $\mathrm{ng} / \mathrm{ml}$

Per log2 higher
$0.89(0.57,1.41)$

0.626 
Table 2 Univariable and multivariable odds ratios for cardiovascular events according to biomarkers in late samples (Continued)

\begin{tabular}{|c|c|c|c|c|}
\hline \multicolumn{5}{|l|}{ hsCRP, mg/L } \\
\hline Per log2 higher & $1.61(1.18,2.18)$ & 0.002 & $1.69(1.09,2.64)$ & 0.020 \\
\hline \multicolumn{5}{|l|}{ IL-6, pg/ml } \\
\hline Per log2 higher & $1.09(0.81,1.45)$ & 0.568 & $1.05(0.72,1.53)$ & 0.799 \\
\hline \multicolumn{5}{|c|}{ P-selectin, ng/ml } \\
\hline Per log2 higher & $2.88(1.38,6.02)$ & 0.005 & $3.14(1.04,9.45)$ & 0.042 \\
\hline
\end{tabular}

multivariable models, a similar association of hsCRP levels with the risk of CVD events was observed after further adjusting for BMI (per $\log _{2}$ higher hsCRP, adjusted OR 1.45 (1.03, 2.04), $\mathrm{p}=0.032$ ), for eGFR (per $\log _{2}$ higher hsCRP, adjusted OR 1.38 [95\% CI 0.97-1.95], $\mathrm{p}=0.071$ ) and for prior use of statins (per $\log _{2}$ higher hsCRP, adjusted OR 1.31 [95\% CI 0.98-1.76], $\mathrm{p}=0.068$ ).

In the main multivariable model including hsCRP as a continuous variable (log scale), and using the combined data set (Table $3 \mathrm{~b}$ ), the following other factors were independently associated with a greater risk of a CVD event: a higher total cholesterol (OR, 3.19 per $1 \mathrm{mmol} / \mathrm{L}$ higher [95\% CI, 1.57 to 6.46]; $P=0.001$ ), a lower HDL cholesterol (OR, 0.06 per $0.5 \mathrm{mmol} / \mathrm{L}$ higher [95\% CI, 0.01 to 0.31]; $P<0.001$ ), a less recent calendar year of the stored sample (OR, 0.92 per 5 years more recent [95\% CI, 0.90 to 0.94]; $P<0.001$ ) and shorter time between the date of sample and the analysis time (OR, 0.91 per month longer [ $95 \% \mathrm{CI}, 0.86$ to 0.96 ]; $P<0.001)$.

\section{Discussion and conclusions}

From the analysis using the combined set of early and late samples, we estimated that elevated hsCRP was associated with increased CVD risk in HIV-positive patients receiving cART (8-fold risk increase comparing patients with hsCRP levels $>3.3 \mathrm{mg} / \mathrm{L}$ with those with $<0.9 \mathrm{mg} / \mathrm{L}$ ). A key finding was that the effect of hsCRP on CVD risk appeared to be independent of traditional CVD risk factors (total cholesterol and low HDL), as well as potential confounders, such as BMI, renal function and use of statins. Increased risk of a CVD event was also evident for higher values of IL-6 and P-selectin, although the association was weaker than for hsCRP. In addition, higher total cholesterol and lower HDL cholesterol were confirmed to be independent predictors of risk of CVD in our HIV-positive population.

The collection of early and late samples provided an opportunity to investigate whether the prognostic value of the studied biomarkers may differ according to specific objectives (i.e. to predict the short-term vs. the long-term risk of CVD). In the unadjusted analysis, median hsCRP levels were higher in cases (i.e. with CVD events) than controls (i.e. without CVD events) for both early and late samples, and more cases had hsCRP levels in the highest vs. lowest tertile, although this difference was more significant in late samples. Numerical problems due to sparse data in the analysis including only early samples, did not allow the calculation of adjusted estimates in this subset. Despite this limitation, our findings suggest that in HIV-infected patients hsCRP may be a useful marker to predict the medium-to-long term risk of experiencing CVD events (22 months after the date of measurement, on average), although the crude association of this marker with CVD events was actually stronger for the short term.

Several studies have investigated hsCRP levels in HIV-positive patients, and the association between hsCRP and CVD risk. HsCRP levels were not statistically different between untreated HIV-infected and uninfected individuals in one study [40], while in another, CRP levels were higher in HIV-positive patients than the general population [41]. Approximately $30 \%$ of patients with HIV receiving long-term cART were shown to have CRP levels $>3.0 \mathrm{mg} / \mathrm{L}$ [41], the highest CRP levels being observed in those who were currently treated with ART [42]. Furthermore, elevated hsCRP levels have been observed in ART-treated compared with ART-na ïve HIV-positive patients in another study [43].

In the analysis by Triant et al. including HIV-positive and -negative patients enrolled in a large US healthcare system, elevated CRP levels were associated with more than a four-fold increase in the risk of acute myocardial infarction compared with HIV-negative patients with normal CRP [44], but the study used either CRP or hsCRP tested by different assays, thus not allowing the analysis of specific thresholds. In a large international study, the baseline levels of CRP were independently associated with CVD events, including myocardial 
Table 3 Univariable and multivariable OR for CVD risk and biomarkers in early and late samples combined Biomarkers Unadjusted OR (95\% Cl) $P$ value Adjusted $^{*}$ OR $(95 \% \mathrm{Cl})$ $P$ value

(a)

Biomarkers as categorical variables

\section{$\mathrm{t}-\mathrm{PA}, \mathrm{ng} / \mathrm{ml}$}

$<=8.7(\mathrm{n}=61)$

8.7-14.8 $(n=60)$

1.00

$>14.8(n=62)$

Not measured $(n=16)$

PAl-1, ng/ml

$<=112(\mathrm{n}=63)$

$112-207(n=61)$

$>207(n=65)$

Not measured $(n=12)$

\section{D-dimer, $\mathbf{n g} / \mathrm{ml}$}

$<=67(\mathrm{n}=48)$

67-125 $(n=48)$

$>125(n=49)$

Not measured $(n=31)$

hsCRP, mg/L

$<0.9(\mathrm{n}=60)$

$0.9-3.3(n=62)$

$>3.3(n=61)$

Not measured $(n=17)$

\section{IL-6, pg/ml}

$<0.3(\mathrm{n}=62)$

$0.3-1.9(n=62)$

$>1.9(\mathrm{n}=64)$

Not measured $(n=13)$

\section{P-selectin, $\mathrm{ng} / \mathrm{ml}$}

$<157(n=62)$

$157-236(n=62)$

$>236(\mathrm{n}=64)$

Not measured $(n=13)$
$3.87(1.61,9.31)$

$3.23(1.35,7.76)$

$3.92(1.42,10.84)$

$1.03(0.45,2.32)$

$1.87(0.86,4.04)$

$1.70(0.62,4.64)$

1.00

$0.71(0.30,1.72)$

$0.71(0.30,1.72)$

$1.27(0.58,2.76)$

1.00

$1.90(0.81,4.46)$

$3.63(1.59,8.29)$

$2.29(0.84,6.28)$

1.00

$1.89(0.81,4.41)$

$3.94(1.74,8.90)$

$2.69(0.94,7.67)$

1.00

$0.95(0.42,2.13)$

$1.95(0.91,4.17)$

$1.57(0.58,4.26)$
0.003

0.009

0.008

0.950

0.113

0.300

0.451

0.450

0.552

0.142

0.002

0.107

0.143

$<.001$

0.065

0.898

0.085

0.378
1.00

$1.58(0.33,7.65)$

0.571

$0.66(0.12,3.75)$

0.642

$0.81(0.09,7.07)$

0.853

\subsection{0}

$1.94(0.37,10.33)$

0.435

$2.15(0.48,9.63)$

0.318

$0.52(0.04,7.73)$

0.637

1.00

$0.49(0.10,2.27)$

0.360

$1.03(0.18,5.80)$

0.972

$1.01(0.21,4.84)$

0.987

1.00

$5.70(1.00,32.51)$

0.050

$8.00(1.23,51.94)$

0.029

$0.94(0.06,15.95)$

0.968

$$
1.00
$$

$2.69(0.54,13.40)$

0.227

$6.91(1.21,39.49) \quad 0.030$

$0.92(0.06,14.95)$

0.954

1.00

$1.45(0.29,7.30) \quad 0.649$

$6.20(1.07,35.89) \quad 0.042$

$0.66(0.04,10.09) \quad 0.766$

(b)

Biomarkers as continuous variables (Log Scale)

\section{t-PA, ng/ml}

per $\log _{2}$ higher

$1.68(1.09,2.59)$

0.019

$1.15(0.52,2.56)$

0.736

PAl-1, ng/ml

per $\log _{2}$ higher

$1.12(0.84,1.48)$

0.449

$1.20(0.71,2.04)$

0.498

D-dimer, $\mathrm{ng} / \mathrm{ml}$

per $\log _{2}$ higher

$1.01(0.79,1.31)$

0.911

$0.89(0.57,1.38)$

0.598

hsCRP, mg/l

per $\log _{2}$ higher

$1.37(1.14,1.66)$

$<.001$

$1.54(1.03,2.30)$

0.036 
Table 3 Univariable and multivariable OR for CVD risk and biomarkers in early and late samples combined (Continued)

\begin{tabular}{|c|c|c|c|c|}
\hline \multicolumn{5}{|l|}{ IL-6, pg/ml } \\
\hline per $\log _{2}$ higher & $1.08(0.90,1.30)$ & 0.408 & $1.22(0.85,1.74)$ & 0.281 \\
\hline \multicolumn{5}{|c|}{ P-selectin, ng/ml } \\
\hline per $\log _{2}$ higher & $1.70(1.05,2.75)$ & 0.032 & $3.35(1.20,9.38)$ & 0.022 \\
\hline
\end{tabular}

infarction, stroke, coronary revascularization, congestive heart failure, CVD death and peripheral artery disease [34] The present study substantiates their results in the Italian setting, using a standardized method for hsCRP determination, and identifies $3.3 \mathrm{mg} / \mathrm{L}$ as a potential threshold associated with an increased CVD risk in the HIV-infected population. Moreover, we were able to confirm the association between CRP and CVD risk after controlling for eGFR, a factor potentially associated with both inflammation and CVD risk. However, in disagreement with these findings, Ford et al. showed no association between hsCRP and CVD events in treated HIV-positive patients [2], while hsCRP was elevated in individuals who were at low risk of a CVD event in the study by Boger et al. [45].

Similar to hsCRP, IL-6 is a marker of inflammation and has been associated with coronary heart disease and endothelial dysfunction [46]: therefore its association with cardiovascular events in this study is not unexpected. An even stronger association between IL- 6 and myocardial infarction has been observed in a previous large study [34]. Plasma P-selectin is almost exclusively secreted by platelets and is associated with platelet activation, blood cell endothelial adhesion and increased cardiovascular risk, in HIV negative patients [47].

The limitations of the current study include the inability to assess the risk of CVD associated with gender (only 9 females were included) and the matching variables (smoking status and diabetes). Also, we were unable to control our estimates for potential differences in systolic blood pressure because a measure of this parameter was available only in a minority of the patients studied (not shown). Furthermore, time from baseline was not one of the matching criteria as it is generally the case in case-control studies nested within a prospective cohort, although cases and controls were matched within the same cohort. In addition, controls have been, on average, exposed to cART for longer than cases (by inclusion criteria, controls had to have received CART for at least 5 years prior to the analysis time while there was no such restriction for cases), and, as a consequence, biomarkers have been measured in more recent calendar years. However, both factors were controlled for in the multivariable analysis. Another limitation relates to the different number of samples contributed by patients to the analysis, although there were only minimal imbalances. Finally, the fact that no association was found between t-PA, PAI-1 or D-dimer and CVD risk in this study does not exclude their role, as the study was not powered to detect such associations.

The importance of evaluating, preventing and managing CVD in patients with HIV is recognized in guidelines for the use of antiretroviral agents in HIVinfected adults [48]. Because hsCRP is cheap to measure and easily available it may become a clinically useful tool to monitor CVD risk in HIV-positive patients. Nevertheless, it has to be said that despite the fact that hsCRP was found to be associated with the risk of cardiovascular events independently of traditional risk factors in the HIV-uninfected population, the role of this biomarker in improving the prediction of CVD of traditional risk scores remains controversial even in the general population [49]. Moreover, several caveats apply: substantial intra-individual variation in hsCRP levels may represent a problem although, in the context of the general population, the predictive value of single measures of this marker was similar to that of repeated measures in the same subjects; evidence showing that lowering hsCRP reduces CVD events is available but not always consistent, calling into question whether hsCRP is a relevant therapeutic target; in addition, in a recent meta-analysis, CRP was associated with a range of disorders, and not just CVD [50].

In summary, our analysis shows that hsCRP is a candidate biomarker predicting CVD risk in HIV-infected patients receiving ART. Additional studies analyzing the influence of the addition of this marker on the prediction of cardiovascular risk scores are required before implementation of routine measuring for the scope of prediction into clinical practice. 


\section{Appendix}

\section{Members of the ICONA Foundation Study \\ Governing body}

M. Moroni (Chair), G Angarano, A Antinori, F Castelli, R Cauda, A d'Arminio Monforte, G Di Perri, M Galli, R Iardino, G Ippolito, A Lazzarin, CF Perno, O Armignacco, PL Viale, F Von Schlosser.

\section{Scientific secretary}

A d'Arminio Monforte

\section{Steering committee}

A Ammassari, M Andreoni, A Antinori, C Balotta, P Bonfanti, S Bonora, M Borderi, MR Capobianchi, A Castagna, F Ceccherini-Silberstein, P Cinque, A CozziLepri, A d'Arminio Monforte, A De Luca, M Gargiulo, C Gervasoni, E Girardi, A Gori, G Guaraldi, M Lichtner, S Lo Caputo, G Madeddu, F Maggiolo, G Marchetti, S Marcotullio, L Monno, R Murri, C Mussini, M Puoti, C Torti

\section{Statistical and monitoring team}

A Cozzi-Lepri, P Cicconi, I Fanti, T Formenti, L Galli, P Lorenzini

\section{Participating physicians and centers}

Italy A. Giacometti, A Costantini, A. Riva (Ancona); G. Angarano, L Monno, C Carrisa, (Bari); F. Maggiolo, G Lazzari (Bergamo); PL. Viale, M Borderi, G. Verucchi (Bologna); F Castelli, C. Torti, C. Minardi, (Brescia); T. Quirino, C Abeli (Busto Arsizio); P.E. Manconi, P. Piano (Cagliari); J Vecchiet, K Falasca (Chieti); L. Sighinolfi, D. Segala (Ferrara); F. Mazzotta, S. Lo Caputo (Firenze); G. Cassola, G Viscoli, A. Alessandrini, R. Piscopo, G Mazzarello (Genova); C. Mastroianni, V. Belvisi (Latina); P. Bonfanti, I. Caramma (Lecco); A. Chiodera, P. Castelli (Macerata); M Galli, A. Lazzarin, G. Rizzardini, M. Puoti, A. d'Arminio Monforte, AL Ridolfo, R Piolini, A Castagna, S Salpietro, A Galli, A Bigoloni, V Spagnuolo, L Carenzi, P Zucchi, M.C. Moioli, R Rossotti, P Cicconi, T Formenti (Milano); C. Mussini, L Bisio (Modena); A Gori, G Lapadula (Monza), N. Abrescia, A. Chirianni, MG Guida, M Gargiulo (Napoli); F Baldelli, B Belfiori (Perugia); G. Parruti, T Ursini (Pescara); G. Magnani, M. A. Ursitti (Reggio Emilia); R. Cauda, M Andreoni, A. Antinori, V Tozzi, V. Vullo, A. De Luca, A. d'Avino, M. Zaccarelli, L Gallo, E. Nicastro, R. Acinapura, M Capozzi, R Libertone, M. Lichtner, G Tebano, (Roma); M.S. Mura, G Madeddu (Sassari); P. Caramello, G. Di Perri, G.C. Orofino, M Sciandra (Torino); G. Pellizzer, V. Manfrin (Vicenza).

Ethics Committees of the Clinical Centers participating to the ICONA Foundation Study

Spedali Civili - P.zza Spedali Civili, 125125 - Brescia

Ospedale Amedeo di Savoia - C.so Svizzera, 164-10149 Torino

Ospedale A Manzoni - Via dell'Eremo 9/11 - 22053 Lecco
Ospedale Busto Arsizio - Piazzale Solaro, 3-21052

Busto Arsizio (VA)

Policlinico Sant'Orsola Università di Bologna - Via Massarenti, 11-40138 Bologna

Arcispedale S Maria Nuova - V.le Risorgimento, 80 42100 Reggio Emilia

Azienda Policlinico di Modena -Via del Pozzo, 7141100 - Modena

Azienda Ospedaliero Universitaria di Ferrara Via Aldo Moro, 8 44124 Cona - Ferrara

Università Politecnica Marche - Ospedale Umberto I L. go Cappelli, 1-60121 Ancona

Azienda Ospedaliera Universitaria Osp Riuniti di Ancona - 60020 - Torrette di Ancona

Presidio Ospedaliero AUSL 9 - Via Santa Lucia 62100 Macerata

Istituto Nazionale per le Malattie Infettive IRCCS "L Spallanzani "-Via Portuense, 292-00149 Roma

Università di Perugia Policlinico Monteluce - Via A. Brunamonti - 06122 Perugia

Policlinico Umberto I, Univ La Sapienza - V.le del Policlinico, 155-00163 Roma

Fondazione PTV - Policlinico Tor Vergata - Viale Oxford, 81-00133 Roma

Università “Aldo Moro” - P. le G. Cesare, 11-70124 Bari

Azienda Ospedaliera Cotugno - Via G. Quagliarello 80131 Napoli

Università "G D’Annunzio" - Via Valignani - 66100 Chieti

USL di Pescara VIA FONTE ROMANA, N ${ }^{\circ} 8-65124$ PESCARA

\section{Competing interests}

$A D L$ received speaker honoraria and fees for attending advisory boards from ViiV Healthcare, Gilead, Abbott Virology, Janssen and Siemens Diagnostics. MC has been a paid consultant for Merck Sharp \& Dohme, Italy and has been employed by Bristol-Myers-Squibb, Italy since May $10^{\text {th }}, 2010$ to Feb $28^{\text {th }}$ 2011. ADM received speaker honoraria and fees for attending advisory boards from GlaxoSmithKline, Gilead, Bristol-Myers-Squibb, BoehringerIngelheim, Abbott Virology, Tibotec.

No other member of the Icona Foundation Study has any financial or personal relationships with people or organizations that could inappropriately influence this work, although most members of the group have, at some stage in the past, received funding from a variety of pharmaceutical companies for research, travel grants, speaking engagements or consultancy fees.

\section{Authors' contributions}

Conception and design: ADL, KGD, MC, Ad'AM. Analysis and interpretation of the data: $A C-L, A D L, L I, A D C, A d$ 'AM. Critical review and revision of the article for scientific accuracy and intellectual content: all. Final approval of the article: all. Statistical expertise: AC-L. Administrative, technical or logistic support: MC, RC, Ad'AM. Collection and assembly of data: ADC, MC, KGD, MP, AC-L, Ad'AM, AG, FG, GS.

\section{Acknowledgments}

We thank Dr Susan Brackenridge who provided medical writing of the initial draft of this manuscript on behalf of the ICONA Foundation Study. 


\section{Role of the funding source}

The Icona Foundation Study is supported by unrestricted educational grants from Abbvie, Bristol-Myers-Squibb, Gilead, ViiV Healthcare, Janssen, Merck Sharp and Dohme. The funding sources had no role in the study design, conduct or analyses, and were not involved in the decision to submit the manuscript for publication.

Primary results of this paper were presented at the 12th European Aids Conference EACS 2009 in Cologne (Germany).

\section{Author details}

'University Division of Infectious Diseases, University Hospital of Siena, Siena, Italy. ${ }^{2}$ Institute of Clinical Infectious Diseases, Catholic University, Rome, Italy. ${ }^{3}$ Research Department of Infection and Population Health, University College London, London, UK. ${ }^{4}$ Department of Epidemiology and Prevention, IRCCS Istituto Neurologico Mediterraneo Nueromed, Laboratory of Molecular and Nutritional Epidemiology, Pozzilli (IS), Italy. ${ }^{5}$ Department of Infectious Diseases, Hospital of Monza, Monza, Italy. ${ }^{6}$ Department of Infectious Diseases, Hospital of Ferrara, Ferrara, Italy. ${ }^{7}$ Department of Infectious Diseases, Marche Polytechnic University, Ancona, Italy. ${ }^{8}$ Department of Virology, IRCCS Ospedale Lazzaro Spallanzani, Rome, Italy. ${ }^{9}$ Institute of Infectious and Tropical Medicine, University of Milan, Milan, Italy. ${ }^{10}$ Istituto di Clinica delle Malattie Infettive, Università Cattolica del Sacro Cuore, Largo F Vito 1, 00168, Roma, Italy.

Received: 13 March 2013 Accepted: 30 August 2013 Published: 3 September 2013

\section{References}

1. Palella FJ Jr, Delaney KM, Moorman AC, Loveless MO, Fuhrer J, Satten GA, Aschman DJ, Holmberg SD: Declining morbidity and mortality among patients with advanced human immunodeficiency virus infection. HIV Outpatient Study Investigators. N Engl J Med 1998, 338:853-860.

2. Ford ES, Greenwald JH, Richterman AG, Rupert A, Dutcher L, Badralmaa Y, Natarajan V, Rehm C, Hadigan C, Sereti I: Traditional risk factors and D-dimer predict incident cardiovascular disease events in chronic HIV infection. AIDS 2010, 24:1509-1517.

3. Currier JS, Lundgren JD, Carr A, Klein D, Sabin CA, Sax PE, Schouten JT, Smieja M, Working Group 2: Epidemiological evidence for cardiovascular disease in HIV-infected patients and relationship to highly active antiretroviral therapy. Circulation 2008, 118:e29-e35.

4. Triant VA, Lee H, Hadigan C, Grinspoon SK: Increased acute myocardial infarction rates and cardiovascular risk factors among patients with human immunodeficiency virus disease. J Clin Endocrinol Metab 2007. 92:2506-2512

5. Law MG, Friis-Møller N, El-Sadr WM, Weber R, Reiss P, D'Arminio Monforte A, Thiébaut R, Morfeldt L, De Wit S, Pradier C, Calvo G, Kirk O, Sabin CA, Phillips AN, Lundgren JD, D:A:D Study Group: The use of the Framingham equation to predict myocardial infarctions in HIV-infected patients: comparison with observed events in the D:A:D Study. HIV Med 2006, 7:218-230.

6. Maggi P, Quirino T, Ricci E, De Socio GV, Gadaleta A, Ingrassia F, Perilli F, Lillo A, Bonfanti P: Cardiovascular risk assessment in antiretroviral-naïve HIV patients. AIDS Patient Care STDS 2009, 23:809-813.

7. Teitel JM, Shore A, Read SE, Schiavone A: Immune function of vascular endothelial cells is impaired by HIV. J Infect Dis 1989, 160:551-552.

8. Zietz C, Hotz B, Stürzl M, Rauch E, Penning R, Löhrs U: Aortic endothelium in HIV-1 infection: chronic injury, activation, and increased leukocyte adherence. Am J Pathol 1996, 149:1887-1898.

9. de Gaetano DK, Rabagliati R, lacoviello L, Cauda R: HIV infection, HAART, and endothelial adhesion molecules: current perspectives. Lancet Infect Dis 2004, 4:213-222.

10. de Gaetano DK, Rabagliati R, Tumbarello M, Tacconelli E, Amore C, Cauda R, lacoviello $L$ : Increased soluble markers of endothelial dysfunction in HIV-positive patients under highly active antiretroviral therapy. AIDS 2003, 17:765-768.

11. Currier JS, Taylor A, Boyd F, Dezii CM, Kawabata H, Burtcel B, Maa JF, Hodder S: Coronary heart disease in HIV-infected individuals. J Acquir Immune Defic Syndr 2003, 33:506-512.

12. Bergersen BM: Cardiovascular risk in patients with HIV Infection: impact of antiretroviral therapy. Drugs 2006, 66:1971-1987.
13. Wolf K, Tsakiris DA, Weber R, Erb P, Battegay M, Swiss HIV Cohort Study: Antiretroviral therapy reduces markers of endothelial and coagulation activation in patients infected with human immunodeficiency virus type 1. J Infect Dis 2002, 185:456-462.

14. Torriani FJ, Komarow L, Parker RA, Cotter BR, Currier JS, Dubé MP, Fichtenbaum CJ, Gerschenson M, Mitchell CK, Murphy RL, Squires K, Stein JH, ACTG 5152s Study Team: Endothelial function in human immunodeficiency virus-infected antiretroviral-naive subjects before and after starting potent antiretroviral therapy: The ACTG (AIDS Clinical Trials Group) Study 5152s. J Am Coll Cardiol 2008, 52:569-576.

15. Worm SW, Sabin C, Weber R, Reiss P, El-Sadr W, Dabis F, De Wit S, Law M, Monforte AD, Friis-Møller N, Kirk O, Fontas E, Weller I, Phillips A, Lundgren J: Risk of myocardial infarction in patients with HIV infection exposed to specific individual antiretroviral drugs from the 3 major drug classes: the data collection on adverse events of anti-HIV drugs (D:A:D) study. J Infect Dis 2010, 201:318-330

16. Lang S, Mary-Krause M, Cotte L, Gilquin J, Partisani M, Simon A, Boccara F, Costagliola D, Clinical Epidemiology Group of the French Hospital Database on HIV: Impact of individual antiretroviral drugs on the risk of myocardial infarction in human immunodeficiency virus-infected patients: a casecontrol study nested within the French Hospital Database on HIV ANRS cohort CO4. Arch Intern Med 2010, 170:1228-1238.

17. Friis-Møller $N$, Weber $R$, Reiss $P$, Thiébaut $R$, Kirk O, D'Arminio Monforte $A$, Pradier C, Morfeldt L, Mateu S, Law M, El-Sadr W, De Wit S, Sabin CA, Phillips AN, Lundgren JD, DAD study group: Cardiovascular disease risk factors in HIV patients--association with antiretroviral therapy. Results from the DAD study. AIDS 2003, 17:1179-1193.

18. Stein $\mathrm{JH}$, Klein MA, Bellehumeur JL, McBride PE, Wiebe DA, Otvos JD, Sosman JM: Use of human immunodeficiency virus-1 protease inhibitors is associated with atherogenic lipoprotein changes and endothelial dysfunction. Circulation 2001, 104:257-262.

19. Holmberg SD, Moorman AC, Williamson JM, Tong TC, Ward DJ, Wood KC, Greenberg AE, Janssen RS: HIV Outpatient Study (HOPS) investigators. Protease inhibitors and cardiovascular outcomes in patients with HIV-1. Lancet 2002, 360:1747-1748.

20. DAD Study Group, Friis-Møller N, Reiss P, Sabin CA, Weber R, Monforte A, El-Sadr W, Thiébaut R, De Wit S, Kirk O, Fontas E, Law MG, Phillips A, Lundgren JD: Class of antiretroviral drugs and the risk of myocardial infarction. N Engl J Med 2007, 356:1723-1735.

21. Wilson SL, Scullard G, Fidler SJ, Weber JN, Poulter NR: Effects of HIV status and antiretroviral therapy on blood pressure. HIV Med 2009, 10:388-394.

22. D:A:D Study Group, Sabin CA, Worm SW, Weber R, Reiss P, El-Sadr W, Dabis F, De Wit S, Law M, D'Arminio Monforte A, Friis-Møller N, Kirk O, Pradier C, Weller I, Phillips AN, Lundgren JD: Use of nucleoside reverse transcriptase inhibitors and risk of myocardial infarction in HIV-infected patients enrolled in the D:A:D study: a multi-cohort collaboration. Lancet 2008, 371:1417-1426.

23. Behrens GM, Reiss P: Abacavir and cardiovascular risk. Curr Opin Infect Dis 2010, 23:9-14

24. Ridker PM: Clinical application of C-reactive protein for cardiovascular disease detection and prevention. Circulation 2003, 107:363-369.

25. Ridker PM, Cannon CP, Morrow D, Rifai N, Rose LM, McCabe CH, Pfeffer MA, Braunwald E, Pravastatin or Atorvastatin Evaluation and Infection Therapy-Thrombolysis in Myocardial Infarction 22 (PROVE IT-TIMI 22) Investigators: C-reactive protein levels and outcomes after statin therapy. N Engl J Med 2005, 352:20-28.

26. McMurray JJ, Kjekshus J, Gullestad L, Dunselman P, Hjalmarson A, Wedel H, Lindberg M, Waagstein F, Grande P, Hradec J, Kamenský G, Korewicki J, Kuusi T, Mach F, Ranjith N, Wikstrand J, CORONA Study Group: Effects of statin therapy according to plasma high-sensitivity C-reactive protein concentration in the Controlled Rosuvastatin Multinational Trial in Heart Failure (CORONA): aretrospective analysis. Circulation 2009, 120:2188-2196.

27. Lowe GD: Fibrin D-dimer and cardiovascular risk. Semin Vasc Med 2005, 5:387-398.

28. Asselbergs FW, Williams SM, Hebert PR, Coffey CS, Hillege HL, Navis G, Vaughan DE, van Gilst WH, Moore JH: Gender-specific correlations of plasminogen activator inhibitor-1 and tissue plasminogen activator levels with cardiovascular disease-related traits. J Thromb Haemost 2007, 5:313-320.

29. Zakynthinos E, Pappa N: Inflammatory biomarkers in coronary artery disease. J Cardiol 2009, 53(3):317-333. 
30. Pearson TA, Mensah GA, Alexander RW, Anderson JL, Cannon RO 3rd, Criqui M, Fadl YY, Fortmann SP, Hong Y, Myers GL, Rifai N, Smith SC Jr, Taubert K, Tracy RP, Vinicor F, Centers for Disease Control and Prevention, American Heart Association: Markers of inflammation and cardiovascular disease: application to clinical and public health practice: a statement for healthcare professionals from the Centers for Disease Control and Prevention and the American Heart Association. Circulation 2003, 107:499-511.

31. Duprez DA, Kuller LH, Tracy R, Otvos J, Cooper DA, Hoy J, Neuhaus J, Paton NI, Friis-Moller N, Lampe F, Liappis AP, Neaton JD, INSIGHT SMART Study Group: Lipoprotein particle subclasses, cardiovascular disease and HIV infection. Atherosclerosis 2009, 207:524-529.

32. Mastroianni CM, Lichtner M, Mengoni F, D'Agostino C, d'Ettorre G, Forcina G, Santopadre P, Massetti AP, Vullo V: Changes in circulating levels of soluble cell adhesion molecules following highly active antiretroviral treatment of HIV-1-infected patients. Clin Immunol 2000, 95:212-217.

33. Tungsiripat M, Adell J, McComsey GA: Relationship between inflammatory markers, endothelial activation markers, and carotid intima-media thickness in HIV-infected patients receiving antiretroviral therapy. Clin Infect Dis 2009, 49:1119-1127.

34. Duprez DA, Neuhaus J, Kuller LH, et al: Inflammation, coagulation and cardiovascular disease in HIV-infected individuals. PLoS One 2012, 7:e44454.

35. Di Giambenedetto S, Bracciale L, Colafigli M, Cattani P, Pinnetti C, Bacarelli A, Prosperi M, Fadda G, Cauda R, De Luca A: Declining prevalence of HIV-1 drug resistance in treatment-failing patients: a clinical cohort study. Antivir Ther 2007, 12:835-839.

36. d'Arminio Monforte A, Lepri AC, Rezza G, Pezzotti P, Antinori A, Phillips AN, Angarano G, Colangeli V, De Luca A, Ippolito G, Caggese L, Soscia F, Filice G, Gritti F, Narciso P, Tirelli U, Moroni M: Insights into the reasons for discontinuation of the first highly active antiretroviral therapy (HAART) regimen in a cohort of antiretroviral naïve patients. I.CO.N.A. Study Group. Italian Cohort of Antiretroviral-Naïve Patients. AIDS 2000 14:499-507.

37. Sasieni P: A note on the presentation of matched case-control data. Stat Med 1992, 11:617-620

38. Greenland S, Schwartzbaum JA, Finkle WD: Problems due to small samples and sparse data in conditional logistic regression analysis. Am J Epidemiol 2000, 151:531-539.

39. Zeger SL, Liang KY: Longitudinal data analysis for discrete and continuous outcomes. Biometrics 1986, 42:121-130.

40. Baker J, Ayenew W, Quick H, Hullsiek KH, Tracy R, Henry K, Duprez D, Neaton JD: High-density lipoprotein particles and markers of inflammation and thrombotic activity in patients with untreated HIV infection. J Infect Dis 2010, 201:285-292.

41. Noursadeghi M, Miller RF: Clinical value of C-reactive protein measurements in HIV-positive patients. Int J STD AIDS 2005, 16:438-441.

42. Masiá M, Bernal E, Padilla S, Graells ML, Jarrín I, Almenar MV, Molina J, Hernández I, Gutiérrez F: The role of C-reactive protein as a marker for cardiovascular risk associated with antiretroviral therapy in HIV-infected patients. Atherosclerosis 2007, 195(1):167-171.

43. Guimarães MM, Greco DB, Figueiredo SM, Fóscolo RB, Oliveira AR Jr, Machado $L$ : High-sensitivity C-reactive protein levels in HIV-infected patients treated or not with antiretroviral drugs and their correlation with factors related to cardiovascular risk and HIV infection. Atherosclerosis 2008, 201(2):434-439.

44. Triant VA, Meigs JB, Grinspoon SK: Association of C-reactive protein and HIV infection with acute myocardial infarction. J Acquir Immune Defic Syndr 2009, 51:268-273.

45. Boger MS, Shintani A, Redhage LA, Mitchell V, Haas DW, Morrow JD, Hulgan T: Highly sensitive C-reactive protein, body mass index, and serum lipids in HIV-infected persons receiving antiretroviral therapy: a longitudinal study. J Acquir Immune Defic Syndr 2009, 52(4):480-487.

46. Erzen B, Sabovic M, Sebestjen M, Keber I, Poredos P: Interleukin-6 correlates with endothelial dysfunction in young post-myocardial infarction patients. Cardiology 2007, 107(2):111-116.

47. Blann AD, Nadar SK, Lip GY: The adhesion molecule P-selectin and cardiovascular disease. Eur Heart J 2003, 24:2166-2179.

48. Panel on Antiretroviral Guidelines for Adults and Adolescents: Guidelines for the use of antiretroviral agents in HIV-1-infected adults and adolescents. Department of Health and Human Services. Available at http://aidsinfo.nih.
gov/ContentFiles/AdultandAdolescentGL.pdf. Accessed January 11th 2013. Last updated March 27th 2012.

49. Ben-Yehuda O: High-sensitivity C-reactive protein in every chart? The use of biomarkers in individual patients. J Am Coll Cardiol 2007, 49:2139-2141.

50. Collaboration Emerging Risk Factors, Kaptoge S, Di Angelantonio E, Lowe G, Pepys MB, Thompson SG, Collins R, Danesh J: C-reactive protein concentration and risk of coronary heart disease, stroke, and mortality: an individual participant meta-analysis. Lancet 2010, 375(9709):132-140.

doi:10.1186/1471-2334-13-414

Cite this article as: De Luca et al.: The association of high-sensitivity creactive protein and other biomarkers with cardiovascular disease in patients treated for HIV: a nested case-control study. BMC Infectious Diseases 2013 13:414.

\section{Submit your next manuscript to BioMed Central and take full advantage of:}

- Convenient online submission

- Thorough peer review

- No space constraints or color figure charges

- Immediate publication on acceptance

- Inclusion in PubMed, CAS, Scopus and Google Scholar

- Research which is freely available for redistribution

Submit your manuscript at www.biomedcentral.com/submit
C) Biomed Central 